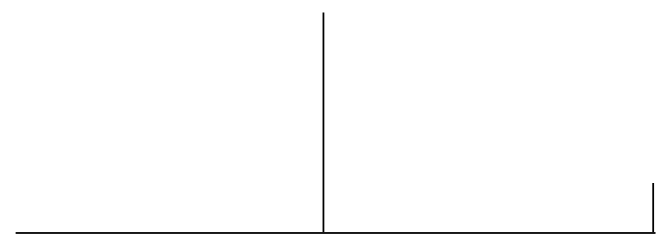

Rev. Latinoam. Psicopat. Fund., São Paulo, v. 15, n. 4, p. 851-867, dezembro 2012

\title{
Dor e gozo: de Freud a Lacan*
}

Edilene Freire de Queiroz

\begin{abstract}
O fenômeno da dor crônica tem obrigado os pesquisadores a ampliarem a compreensão da dor para além do fenômeno sensório e a reconhecerem a dimensãsociocultural e psíquica da dor. Para os psicanalistas a dor é testemunho da presença da pulsão no corpo. Discutiremos o problema da dor e sua aproximação com o gozo na perspectiva da metapsicologia freudiana e lacaniana. $\mathrm{Na}$ perspectiva freudiana, a dor está regida pelo princípio do prazerdesprazer, já na lacaniana o gozo diz respeito ao que está para além deste princípio, ou seja, liga-se à pulsão de morte.
\end{abstract}

Palavras-chave: Dor corporal, pulsão, representação, gozo

*Este trabalho é um dos produtos da pesquisa financiada pelo Conselho Nacional de Desenvolvimento Científico e Tecnológico - CNPq (Brasília, DF, Br), sob o título de $O$ social e as psicopatologias do corpo: problematizando a dor e o gozo. Ele foi apresentado, numa primeira versão bem mais reduzida, na II Jornada de Estudos do CLINP (Grupo de Pesquisas Clínicas Psicanalíticas), Universidade Federal do Rio de Janeiro - UFRJ/ CNPq, sobre Corpo e sintoma na clínica psicanalítica, em 10.11.2009, como intervenção na Mesa-redonda "O que a clínica nos ensina?". 
A dor é considerada o sintoma predominante em $75 \%$ dos pacientes que procuram um hospital geral (Engel, 1975). A síndrome da dor crônica é a principal causa de incapacidade nos Estados Unidos e é considerada um importante problema de saúde pública contemporâneo. No Brasil, o Ministério da Saúde implantou, no SUS, Serviços de tratamento da dor.

Nos últimos cinquenta anos, o fenômeno da dor crônica tem obrigado os pesquisadores a ampliarem a compreensão da dor para além do fenômeno sensório e a reconhecerem a dimensão sociocultural e psíquica da dor, o que vem obrigando os serviços e clínicas de dor a manterem equipes interdisciplinares, a adotarem - em paralelo à prescrição de analgésico ou aplicação de bombas de morfinas no corpo -, a alternativa de tratamento fisioterápico e psicológico.

Podemos conjeturar que as incidências de estados de dor física como as dores corporais e as respostas físico-somáticas seriam estimuladas pela cultura somática atual que privilegia a sensorialidade. A exposição permanente dos sentidos nos torna vulneráveis ao pathos e o excesso de conteúdo sensório, segundo Freud (1977/1950-1895), produz um efeito traumático, justamente pela impossibilidade de o ego poder representá-lo. Os órgãos dos sentidos são "aparelhos para a recepção de certos efeitos específicos de estimulação, mas que também incluem disposições especiais para maior proteção contra quantidades excessivas de estimulação e para a exclusão de tipos inapropriados de estímulos" (Freud, 1977/1926-1925, p. 19). Como o aparelho psíquico está regulado pelo princípio do prazer é função do ego proteger-se contra o excesso de excitação que gera uma tensão desagradável. "A proteção contra os estímulos é, para os organismos vivos, uma função quase mais importante do que a recepção deles, mas nem sempre a proteção funciona quando a estimulação é intensa (interna ou externamente) causando desprazer e dor" (ibid.). Numa cultura da sensorialidade é provável que as sensações sejam potencializadas provocando um excesso que causa desprazer e dor.

A dor é definida pela International Association for the Study of Pain (2009) “... como uma experiência sensorial e emocional desagradável, associada a uma lesão tecidual atual ou potencial, ou descrita em termos de 


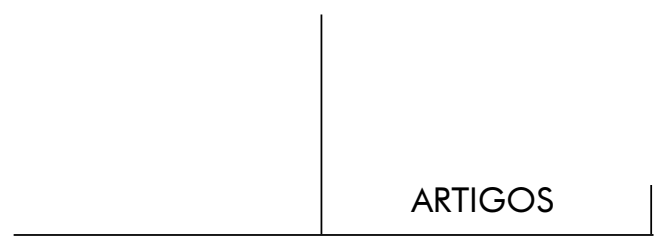

tais lesões". A hipótese, que faz a dor decorrer unicamente de uma lesão tecidual, não se sustenta, pois em situação de guerra, alguns soldados alvejados não sentem dor e continuam no combate. Nesse caso, a dor, que é considerada o alarme do organismo, não aparece.

Evidentemente, em uma vivência tão implacável como a guerra, que instiga a fúria cega dos homens e a vontade de aniquilamento, é compreensível que a dor, causada por qualquer ferimento, seja imperceptível, pois se mistura à devastação da destruição. Freud (1977/1926], p. 197) já havia observado que mesmo a dor física mais intensa deixa de existir quando há um desvio psíquico ocasionado por algum outro interesse. Do mesmo modo, um grande dano físico pode estancar o desenvolvimento de uma neurose por exigir um hiperinvestimento do órgão lesado. Os acontecimentos traumáticos exercem um poderoso efeito na distribuição da libido e como a dor pressupõe a função de reconhecimento pelo ego (ao receber representações de partes do corpo), sua existência, ou não, depende de diferentes fatores psíquicos como teremos oportunidade de desenvolver mais adiante.

A ausência do reconhecimento da dor pode ocorrer em diferentes quadros clínicos, cujo funcionamento psíquico é regido por processos primários, como em alguns quadros psicóticos, em que os sujeitos são capazes de decepar membros sem queixar-se de dor. Quem trabalha com crianças autistas se admira do fato de algumas delas se acidentarem e não reclamarem, nem chorarem. O cérebro, como órgão decodificador, não interpreta essa experiência como dolorosa, mesmo não sendo sujeitos portadores de lesões ou disfunções nos neurônios receptores da dor, ou no hipotálamo (órgão que dá a dimensão afetiva da dor). Portanto, a explicação neuropática da dor não dá conta da complexidade da experiência dolorosa. A dor indica a presença da pulsão no corpo e pressupõe uma organização psíquica na qual o ego pode reconhecê-la. Como a angústia, ela é sinal de perigo e, portanto, está a serviço da pulsão de vida. Nos casos em que a ação da pulsão de morte se sobrepõe a de vida, a dor tende a ser inócua e a transmudar-se em gozo.

Para os psicanalistas, a dor é testemunho da presença da pulsão no corpo. Freud (1977/1926), no Rascunho C de "Inibição, sintoma e ansiedade" que versa sobre Ansiedade, dor e luto, refere-se à dor psíquica como equivalente da dor física, enquanto reação real à perda de um objeto. A dor é um acontecimento de corpo, é metáfora da unidade corpo/psiquismo, como demonstrou Marcos Creder (2002), em um importante estudo sobre a dor, no qual analisa alguns casos de migração da dor: do psíquico para o físico e do físico para o psíquico.

Somente no nível da dor pode-se experimentar toda a dimensão do organismo, toda a dimensão de se ter um corpo e a dimensão trágica da existência. Distinto dos animais, que são só seus corpos, o animal humano se caracteriza por possuir um corpo e também por poder usufrui-lo. Assim, o homem

Rev. Latinoam. Psicopat. Fund., São Paulo, v. 15, n. 4, p. 851-867, dezembro 2012 
vê seu corpo como o Outro de si e pode gozar dele. Segundo Triol, citado por Siqueira (2009), "contrariamente ao reino animal ou vegetal, onde, em geral, a espécie predomina sobre o indivíduo, no homem encontramos o contrário: o desejo do indivíduo prima sobre o da espécie..." (p. 113). Por esta razão, desde Freud, sabemos que o homem não é regido, apenas, por uma ordem instintual e o seu corpo, como expressão da pulsão, assujeita-se à materialidade do significante. Nascemos com um código genético preestabelecido pelas leis naturais (instintos), o qual se transforma pelos significantes do Outro; estes se inscrevem no corpo, produzindo marcas de gozo. A expressão "acontecimento de corpo", cunhada por Lacan, diz respeito justamente a isso, ou seja, ao acontecimento de discurso que deixa traço no corpo. A dor é testemunho da presença da pulsão no corpo e a pulsão, por sua vez, é um vestígio da linguagem que modifica a necessidade. Logo, na experiência de dor, há que se considerar a dimensão do parlêtre, o que será feito na segunda e terceira parte deste texto.

\section{Metapsicologia da dor em Freud}

As causas precipitadoras da dor, segundo Freud (1977/1950-1895), são, por um lado, o aumento da quantidade de excitação sensível, mesmo a dos órgãos sensoriais mais susceptíveis, e, por outro lado, a uma interrupção da continuidade mesmo quando a quantidade de excitação é mínima. A dor está ligada a uma quantidade de investimento mais intenso, o qual rompe as barreiras de contato, que protegem o sujeito dos estímulos excessivos.

Nesse contexto quantitativo da dor, não podemos deixar de reconhecer sua base neuroquímica. Há neurotransmissores que ativam os neurônios excitatórios e outros que liberam substâncias analgésicas, as quais defendem o organismo de dores intensas, que ultrapassam o limiar de suportabilidade - como acontece em certos casos de mutilações.

Existe certa correspondência entre os três sistemas apresentados por Freud (1977/1950-1895) em "Projeto para uma psicologia científica" e o que a neurologia apresenta como a condução do estímulo nervoso. Freud apresenta os neurônios como suporte material e elemento constituinte do aparelho psíquico.

Os neurônios do sistema phi são permeáveis à passagem de quantidade de excitação. São neurônios condutores de excitação, correspondem ao que em neurologia se indica como os nociceptores que liberam os mediadores químicos. Eles compõem o sistema perceptivo, e o contato com o mundo externo é feito pelos órgãos dos sentidos. 


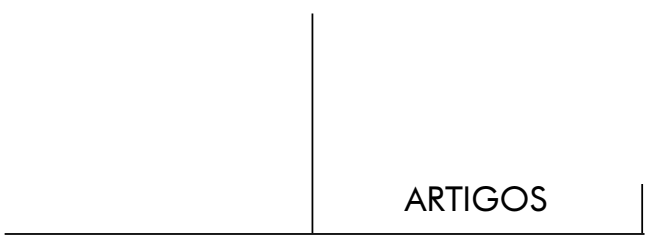

Os neurônios do sistema psi estão relacionados à memória e dizem respeito à inscrição sensitiva da experiência. Eles são dotados de dispositivos de proteção - as barreiras de contato -, que impedem a invasão de grandes quantidades de excitação, tanto exógenas quanto endógenas. Podemos compará-los ao tálamo cerebral que tem a função de filtro e não deixa passar para o córtex sensitivo evitando que o sistema nervoso central tome conhecimento do estímulo doloroso. Ele dispara algumas respostas neuroplásticas. Freud (1977/1950-1895) diz, então, que "o sistema nervoso tem a mais decidida propensão a fugir da dor" (p. 408), pois sua tendência primária é evitar o aumento da tensão quantitativa.

Já os neurônios do sistema ômega produzem as sensações conscientes de prazer e de desprazer. Estão relacionados à capacidade de perceber as qualidades sensórias de dor ou de prazer. Do ponto de vista da neurologia, o hipotálamo - substância cinzenta do córtex cerebral mais primordial e especializada, por onde caminham as informações -, dá a dimensão afetiva e qualitativa da dor. Por meio dele os estímulos sensórios são codificados e reconhecidos pelo sistema nervoso central.

A dor consiste na irrupção de grandes quantidades de excitação em $p s i$ e em ômega. Esses três sistemas envolvem três funções psíquicas importantes: a inscrição da excitação, o registro da experiência sensitiva e o reconhecimento da dor.

Na segunda tópica, esse modelo econômico da dor permanece, mas ela será tratada na perspectiva qualitativa do prazer-desprazer e o que estaria mais além desse princípio. A dor vai estar diretamente relacionada às experiências de desprazer. Em "O problema econômico do masoquismo", Freud (1977/1924) afirma que, além do fator quantitativo, o desprazer tem um componente qualitativo. Este, por sua vez, está relacionado ao funcionamento libidinal, às exigências do princípio do prazer, cuja "missão é tornar inócuo o instinto destruidor" (p. 204) colocando-o para fora e não descarregando-o no próprio corpo e conta com o aparelho motor para operacionalizar essa tarefa. No Rascunho G, sobre a melancolia (1977/1917), ao tratar da dor causada pela perda do objeto, ele a apresenta como uma efração, uma espécie de ruptura dos protetores, dando a sensação de um "a mais" vivido como um buraco no corpo, equivalente a uma ferida [no corpo]. É importante realçar que, em várias passagens, Freud faz questão de fazer corresponder a dor psíquica à dor física. Para ele, o conceito de dor psíquica foi criado pela linguagem. Freud (1977/1915), inclusive, chegou a considerar a dor como uma pseudopulsão, pois ela constitui uma fonte contínua de excitação interna que não se pode evitar pela fuga ou pela descarga de excitação. Os excessos de excitação causadores de tensão desagradável não são resolvidos pela descarga da energia, mas pelo trabalho de ligação da energia desligada.

Toda dor tem uma qualidade especial determinada pela imagem mnêmica a ela associada. A dor é uma experiência universal, mas cada dor é única (Rocha,

Rev. Latinoam. Psicopat. Fund., São Paulo, v. 15, n. 4, p. 851-867, dezembro 2012 
2009). A dor está na base das experiências de repulsa, enquanto o desejo nas de atração. No entanto, presenciamos formas de funcionamento inusitadas nas quais a dor, em vez de funcionar como força repulsiva, funciona como força atrativa como nos casos comumente identificados como masoquismo.

Convém lembrar que Freud distingue três tipos de masoquismo: o erógeno, o feminino e o moral (sentimento de culpa). Todos eles estão subordinados ao princípio do prazer. O masoquismo primário, que está na base de todas essas experiências dolorosas, distinto dos demais, é regido pela ação direta da pulsão de morte, provocando destruição. O masoquismo, subordinado ao princípio do prazer, atrai sem pôr em risco a vida do sujeito, já o primário atrai ao desafiar os limites da vida.

A dor é imperativa, e é somente subjugada pela interferência de uma suspensão tóxica, pela influência de uma digressão psíquica e pela entrada na ordem da linguagem. Um exemplo disso Freud nos deu no jogo do fort-da de seu neto, o qual dominou a dor provocada pela ausência da mãe por meio da linguagem (os fenômenos "ô" e "a") conseguindo, pelo jogo, o domínio da situação de angústia em que se encontrava (Rocha, 2009).

Tivemos outro exemplo dessa influência da digressão psíquica sobre a dor, por meio da linguagem, em um trabalho investigativo de uma mestranda, fisioterapeuta de formação, ao teorizar sobre os componentes subjetivos da dor na fibromialgia (Costa, 2009). Ela acompanhou três pacientes com terapia manipulativa (massagens em pontos dolorosos) e agregou a tal prática a escuta do discurso sobre a dor e sobre suas histórias de vida e pôde verificar, então, as mudanças significativas operadas nas pacientes ao fazer uso da linguagem: houve remissão total das queixas de dor, em uma das pacientes, e remissões parciais, mas significativas, nas outras duas.

A dor, na concepção freudiana, está regida pelo princípio do prazer-desprazer. Se a noção de pulsão de morte deu a Freud a condição de enxergar além do princípio do prazer-desprazer, foi Lacan que nomeou essa dor mais além do princípio do prazer-desprazer como gozo e distinguiu na compulsão de repetição duas conotações. Uma diz respeito à repetição do fato traumático para dominá-lo e significá-lo, ou seja, fazer uma digressão da dor como aconteceu nos exemplos acima. Já na outra a repetição decorre da fixação num traço, ou seja, é o $S_{1}$ que se repete, pois não há endereçamento ao Outro.

\section{Da dor ao gozo}

Nas nossas investigações sobre marcas corporais temos tido oportunidade de refletir sobre jovens que buscam viver experiências de suspensão corporal, 


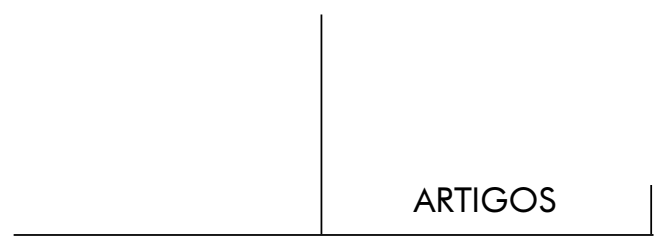

submetendo-se a perfurações e implantes corporais de ganchos. Um caso particular estudado por Pereira (2006) e retomado por Siqueira (2009), chamou a atenção destas pesquisadoras pela maneira como as pessoas, que testemunharam a experiência, descreveram a expressão de um dos jovens que participava da sessão de suspensão. Ele fazia um O-kee-pa (uma das formas de suspensão mais dolorosa e arriscada) e tinha, no seu semblante, uma expressão de gozo, de êxtase e não de dor, como era de se esperar. As pessoas o descrevem como estando em transe e ele pedia para permanecer suspenso, mesmo sabendo do risco. Igual descrição é feita por Lacan (1982[1972-1973]) ao se referir ao gozo dos místicos como uma experiência particular de autoflagelação e prazer intenso e destaca em particular a expressão de gozo estampada na face de Santa Tereza d'Avila retratada na escultura de Bernini sobre $O$ êxtase de Santa Tereza. Esses casos exemplificam a experiência de ultrapassagem para um nível de satisfação que está para além do prazer e do desprazer. Significa que quando se ultrapassa o limiar, não do prazer para o desprazer (dor), mas o limiar da dor, chega-se ao gozo. O depoimento do jovem que fez o $O$-kee-pa sobre a sensação vivida corrobora isso. Diz ele: “... no início vive-se uma dor intensa, mas depois a dor some e fica uma sensação indescritível que invade todo o corpo" (Pereira, 2006, p. 125).

No nosso vernáculo, a dor está associada a uma impressão desagradável e penosa, enquanto o gozo está associado ao desfrutar, ao fruir e ao deliciar-se. Logo, dor e gozo não conotam o mesmo sentido, ambos são fenômenos psicossomáticos e de fronteira. Empregamos o termo "psicossomático" no sentido lato adotado por Assoun (2004), ou seja, como o modo de dar testemunho físico do des-simbólico, ou não simbólico e não no sentido estrito empregado pela Psicossomática ao definir e classificar certas patologias como de caráter psicossomático.

Do ponto de vista estrito do sintoma, temos de considerar dois tipos de "somatização", como efeitos dos acontecimentos que se inscrevem no corpo: a) por efeito de conversão, passando pelo grande circuito pulsional, como fazem as histéricas; b) pelo escoamento direto da pulsão (pelo curto circuito pulsional), sem passar pelo processo de representação como nos casos dos fenômenos psicossomáticos.

A dor está a serviço da pulsão de vida e se representa psiquicamente como experiência de desprazer, enquanto o gozo está a serviço da pulsão de morte e é da ordem do des-simbólico. Dor e gozo estão para além do princípio do prazer: a dor dizendo respeito ao desprazer e o gozo ao que está para além do prazer-desprazer.

A distinção feita por Freud sobre os tipos de masoquismo, conforme apresentamos anteriormente, está delimitada por dois campos de ação da pulsão de morte: num a pulsão de morte encontra-se a serviço da pulsão de vida e, no 
outro, a ação da pulsão de morte se dá sem a mediação do Outro. O primeiro regese pelo princípio do prazer, já o outro, pelo imperativo categórico de um superego arcaico. Essa distinção, no meu entender, levou Lacan a empregar outro significante para indicar essa experiência que está para além do princípio do prazer e do desprazer e que se distingue da dor - o gozo.

Segundo Roudinesco (1998, p. 299), Freud utilizou o termo gozo somente em três passagens: a) quando comenta, a propósito dos invertidos, nos "Três ensaios sobre a teoria da sexualidade", que os homossexuais não conseguem extrair nenhum gozo pelo objeto do sexo oposto; b) em Os chistes e sua relação com o inconsciente e c) em "Mais além do princípio do prazer". Em todas elas, o termo gozo é empregado como sinônimo de prazer. A referência mais próxima ao sentido dado por Lacan aparece ao se referir à dor dos melancólicos como um buraco no corpo. Vê-se aí o germen da noção concebida posteriormente por Lacan.

Inicialmente, a noção de gozo, empregada por Lacan, também estava ligada ao prazer sexual e implicava a ideia de perversão. O perverso sabe fazer gozar. À medida que avançou na teorização do real, Lacan diferenciou a noção de gozo da de prazer. O prazer é da ordem do gozo parcial, submetido ao simbólico.

Lacan (1988/1959-1960), funda o gozo a partir de uma referência ao Das Ding freudiano, ou seja, numa situação anterior a todo significante. Diz ele: o gozo está na coisa enquanto que o desejo está do lado do Outro. O gozo não passa pelo Outro, não passa pela linguagem. O gozo está para além da dor, justamente porque há uma cisão entre aquele que goza e o Outro. Se dor e gozo, do ponto de vista quantitativo, dizem respeito à ultrapassagem do limite de suportabilidade de excitação; do ponto de vista qualitativo, a dor indica a qualidade do desprazer, quando este limite é ultrapassado e se endereça a Outrem; ao passo que o gozo se relaciona ao não limite entre o sujeito e o Outro: ou porque ocorreu uma colagem entre eles, ou porque o Outro foi excluído (gozo autístico). O gozo como não regido pelo princípio do prazer está nas experiências mais arcaicas, representa a experiência repetitiva do chuchar do seio materno na experiência de sucção da criança.

Segundo Nasio (2007), é impossível pensar a existência de um acontecimento sensorial sem que um sujeito o registre sob a forma de uma representação. Essa representação chama-se imagem mental do corpo e significa a transformação do acontecimento sensorial bruto em acontecimento de linguagem. O autor (2008) observa que há "um conjunto de imagens mentais do corpo. E é essa constelação de imagens que nos dá o sentimento de existir em um corpo vivo e de ser eu" (p. 13). Toda sensação percebida imprime inevitavelmente sua imagem, toda sensação real se duplica forçosamente na virtualidade. O corpo real é a matéria viva pulsante, onde nascem as excitações. É o lugar onde se produz o acontecimento sensorial bruto, independente do sujeito. 


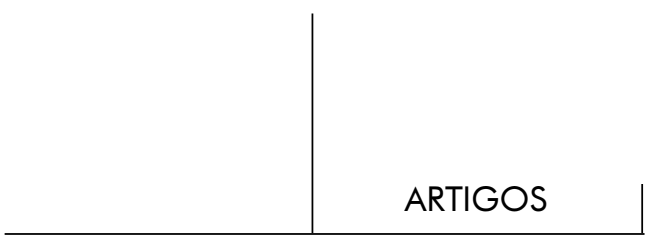

A imagem do sentido é, antes de tudo, a representação da zona corporal, onde se produziu o acontecimento corporal. Algumas vezes essa imagem é nítida, outras vezes confusa, pode ser consciente ou inconsciente, mas, em quaisquer dos casos, ela se grava automaticamente no psiquismo. Entretanto, quando não há a presença interiorizada de outrem, o investimento libidinal não é suficiente para que um acontecimento sensorial seja representado. Ela é gravada, porém não representada. A experiência sensível fica ao nível do curto circuito pulsional, sem ascender ao grande circuito pulsional, onde ocorre o processo de representação. É preciso o afeto e também o Outro para se configurar a experiência de dor. Diz Nasio (2007): "Se eu sofro de uma dor é sempre em referência a outrem" (p. 13).

Porém, quando o sujeito fica petrificado pela doença (acontecimento de corpo), seu corpo se torna fonte ilimitada de gozo, pois, nesse caso, há uma estagnação da libido num certo órgão, ou ponto do corpo, em decorrência de uma forclusão local, como acontece nos fenômenos psicossomáticos. Sabemos que tais fenômenos não possuem a mesma consistência simbólica do sintoma no sentido analítico, ou seja, de uma formação do inconsciente com uma estrutura de linguagem que opera por substituição, deslocamento e modificação. E quando falta significante, quando a palavra deserta do corpo, deixa de existir distância entre o gozo e o corpo, razão pela qual Lacan afirma que o gozo é no corpo e fora da linguagem. Em outras palavras, quando não se representa os acontecimentos sensoriais, quando não se dá sentido a eles, o corpo fica numa relação de exclusão com a cadeia de linguagem e aquilo, que seria experimentado como dor, transforma-se em gozo. Só o significante é capaz de fazer borda ao gozo. O gozo, como a dor, pressupõe a ultrapassagem do limiar, sendo que, no segundo, há certa circunscrição do gozo, limitando-o, fragmentando-o. A dor faz limite entre a experiência de prazer e a de gozo.

Podemos declarar, então, que o gozo é uma instância negativa, diferente do prazer. O prazer é uma barreira ao gozo.

O prazer é a excitação mínima, aquilo que faz desaparecer a tensão, tempera-a ao máximo, ou seja, então, que é aquilo que nos faz parar, necessariamente, a uma distância regulamentar do gozo. Porque aquilo que chamo gozo, no sentido em que o corpo se experimenta, é sempre da ordem da tensão, do forçamento, do gasto e até mesmo da proeza. Há incontestavelmente gozo no nível em que começa a aparecer a dor e nós sabemos que é somente neste nível da dor que pode se experimentar toda uma dimensão do organismo que de outra forma fica velada. (Lacan, 2001/1966, p. 12)

No prazer, existe o Outro pondo limite ao usufruto de todo fruir pulsional. Já o gozo é a face não domada da pulsão e, por isso, ele é da ordem do excesso, da carga pulsional primordial, que permanece no corpo como pontos de 
fixação de experiências sensoriais vividas. São pontos inscritos, mas não significantes.

\section{A metapsicologia do gozo em Lacan}

Os estudiosos de Lacan têm assinalado o modo, segundo o qual, o trabalho de teorização se desenvolve, ao longo de sua obra, em relação a um dos componentes das três dimensões do aparelho psíquico: RSI. O imaginário tem um destaque privilegiado no começo, depois do simbólico, enquanto que o real só mereceu destaque no curso dos últimos anos.

No Seminário 1 sobre Os escritos técnicos em Freud, no qual Lacan (1979/ 1953-1954) propõe um retorno à Freud, a ênfase está no simbólico, logo as três dimensões estão configuradas como SIR. Mas nele dedica uma atenção especial à tópica do imaginário, na qual apresenta o esquema óptico. $\mathrm{O}$ corpo, por conseguinte, é visto pela ótica do simbólico e do imaginário e igualmente do gozo. Portanto, conceitualmente corpo e gozo ficam velados porque seu objetivo é demonstrar a função da palavra (Miller, 2000). Nesse momento, a frase que caracterizava a concepção de Lacan era: o inconsciente é estruturado como uma linguagem. Assim, ele pretendia dar conta do que é decifrável no inconsciente. Nesse sentido, sua clínica não se diferenciava daquela proposta por Freud, ou seja, o sintoma era efeito do recalque. A decifração simbólica e a satisfação na linguagem tinham um lugar de destaque. Ele concebia a dor e o sofrimento como provocados pelo aprisionamento do sentidentido do gozo era próximo ao do prazer.

Entretanto, não tardou muito para ele reconhecer que o simbólico não é tudo, pois deixa de fora o imaginário que é outra ordem de realidade e de satisfação. O imaginário permanece fora da apreensão simbólica, mas, ao mesmo tempo, é dominado por ela. O gozo imaginário só aparece quando há ruptura na cadeia simbólica, pois dele o inconsciente não pode falar. No trabalho clínico, isto significa anular ou apagar o gozo, restituindo-o sob a forma de desejo significado.

No Seminário A ética da psicanálise (Lacan, 1988/1959-1960) ele trata o gozo como estruturalmente inacessível, fora de todo significante, como o Das Ding freudiano. O gozo está do lado da coisa, num lugar abissal, como diz Miller (2000), não como abismo, e sim como uma pequena cavidade, representado pelo objeto pequeno a (objeto que encarna e reproduz a coisa). Creio que esta concepção é antecipada por Freud (1977 [1917-1915]) quando apresenta, em "Luto e melancolia", a dor como uma efração, como um "a mais" vivido como um buraco no corpo. Lacan quer dizer com isso que a verdadeira satisfação pulsional não está nem do lado do simbólico nem do lado do imaginário, ela é da ordem do real. 


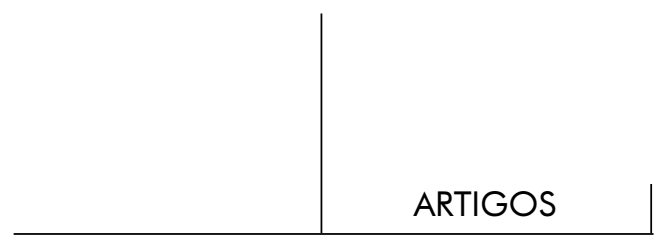

Se, no segundo momento, ele tenta decifrar o gozo imaginário pelo simbólico, com o reconhecimento do gozo como real, este passa a ser visto como da ordem do impossível.

A entrada do real provoca uma revolução no pensamento de Lacan. O aforismo - "o inconsciente estruturado como uma linguagem" - passa a conotar o sentido de uma linguagem primordial do sujeito (alingua), relacionada à experiência de gozo. Ele, então, descreve o inconsciente como uma borda, que se abre e que se fecha na relação com o corpo e com as pulsões mais primitivas. Há, de certo modo. um retorno ao corpo. Assim, corpo e gozo, que estavam conceitualmente velados no seu primeiro ensino, revelam-se no segundo.

A tese - o corpo humano é habitado pela linguagem - permanece e faz com que ele relacione o gozo ao significante. "O significante se situa no nível da substância gozante" (Lacan, 1982/1972-1973, p. 36). O que fica comprometido, nesse caso, é a relação do significante com outro significante, princípio binário necessário à constituição da cadeia simbólica e da linguagem como comunicação. A teorização de Lacan sobre o gozo aproxima-se do conceito de compulsão à repetição, próprio da pulsão de morte, ou seja, quando não há o endereçamento do significante $\left(\mathrm{S}_{1}\right)$ a outro significante $\left(\mathrm{S}_{2}\right)$, o $\mathrm{S}_{1}$ torna-se único, uma marca de gozo que não pode ser pensado, "significantizado". Só resta, então, como operação possível, a repetição do traço unário.

Lacan (1982/1972-1973) trabalha bem isso no Seminário Mais... Ainda.Lá ele mostra a dimensão do "a mais" [do] suplementar no gozo. Ele distingue o gozo fálico do gozo feminino. O primeiro, na fórmula da sexuação, liga-se ao masculino e à função simbólica da castração. Significa o gozo na linguagem. Já o segundo, corresponde à posição feminina, cuja característica fundamental é ser sem limite (a mulher não toda submetida à castração). O gozo estaria fora da linguagem, da relação com o Outro. Ele aproxima deste último a experiência dos místicos e toma a imagem de Santa Teresa d'Avila, de Bernini, como figura paradigmática deste gozo.

Segundo Miller (2000), a fórmula adotada de Pierce, segundo a qual, "o signo representa alguma coisa para alguém", é metamorfoseada no aforismo: "o significante representa o sujeito para outro significante" $\left(S_{1}\right.$ para $\left.S_{2}\right)$, Na clínica do real, este aforismo, parodiando o anterior: "o significante representa o gozo para outro significante", adquire uma nova versão. Nela, a fórmula deixa de ser $\left(\mathrm{S}_{1}\right.$ para $\left.\mathrm{S}_{2}\right)$ e passa a ser $\left(\mathrm{S}_{1}\right.$ para $\left.\mathrm{S}_{1}\right)$. Isso significa que, no gozo, há um apagamento do sujeito ante o mandato do imperativo categórico. Nesta fórmula, o significante perde a função de comunicação, de endereçamento, pois é o significante Um que se repete "gozozamente". Atribui-se essa perda ao fracasso do recalcamento primordial. Ocorre justamente o inverso da experiência primitiva da criança, que primeiramente vive a sensação e as necessidades orgânicas e, pela significação 
dada pela mãe ou substituta, inscreve-as numa relação de comunicação. Com o realce do real do gozo, a palavra, antes apontada como um dado primário, torna-se secundária. Segundo Chemama (1995), comentando Lacan, o gozo está na textura da linguagem, na língua primordial do sujeito humano - a lalangue. Esta é um neologismo lacaniano, espécie de língua do "mais um" e indica um tipo de palavra primordial disjunta da linguagem, mas que se mantém como o real da linguagem.

Observa ele que o significante não tem somente efeito de significado, senão também de afeto em um corpo, ou seja, afeto no sentido daquilo que perturba e que deixa marcas no corpo. O efeito de afeto inclui o efeito de sintoma, o efeito de gozo e inclusive o de sujeito, mas de sujeito situado num corpo.

Nos últimos Seminários (Livros 20, 22 e 23), Lacan abre uma perspectiva nova na maneira de apresentar a articulação do real, do simbólico e do imaginário. Ele apresenta o nó borromeu como suporte dessa estrutura ternária. Há uma espécie de reconciliação com as primeiras noções, pois ele trata os sintomas corporais como podendo ser discutidos pela escrita dos nós RSI: corpo real, corpo simbólico e corpo imaginário. Os signos de gozo são marcas corporais que não podem ser ditas e, sim, mostradas pelo ato, pela maneira do sujeito agir, pelos sintomas, e têm a ver com a experiência de corpo no real. Com isso, não só vinculou o gozo ao real, como renovou a noção de corpo que deixou de ser apenas um conceito para ser uma consistência. Isso significa que não se pode pensar a clínica psicanalítica sem pensar os acontecimentos de corpo. A linguagem deixa traços no corpo e todo sintoma psíquico tem um substrato corporal.

O objeto "a", mesmo sendo concebido como objeto que indica o vazio, o Das Ding, e, portanto, um objeto in-substancial, de consistência lógica, o objeto próprio da pulsão, ele tem um aspecto de extração corporal, que se liga à experiência de corpo despedaçado e aos pequenos objetos de satisfação. Assim, no sintoma mesmo concebido como metáfora, estão presentes os elementos corporais.

\section{À guisa de uma conclusão}

É disso que se trata na clínica contemporânea: tratar sujeitos que usufruem de seus corpos de diferentes modos e, algumas vezes, descomedidamente. São sujeito doloridos, ou gozantes. Os primeiros põem limite ao usufruto do corpo, já os segundos levam o usufruto às últimas consequências. São corpos que prescindem do Outro e tornam-se, eles mesmos, Outros privilegiados. O desafio da clínica é tornar significável a dor. 
Os gregos criaram o trágico no teatro para ajudar aos homens a transformar o sofrimento em fonte de saber (páthos máthos). Eles sabiam que o sofrimento precisa ser significado. A função da ação trágica, personificada no herói, era "purificar" o sofrimento, produzindo uma conversão interna de vivência sensitiva para uma forma de saber que não é teórica. Páthos máthos, que significa sofrimento e conhecimento, pode ser interpretada de dois modos: o conhecimento que se adquire pelo sofrimento e o sofrimento que precisa ser significado.

De outro lado, o desafio é restaurar nesses sujeitos a função egoica de fazer desaparecer a tensão, mas deixando o sujeito a uma distância regulamentar do gozo. É função do ego administrar a economia pulsional, endereçando o gozo às zonas erógenas, pontos localizados e circunscritos. É função do ego regenerar o narcisismo, pondo a pulsão de morte a serviço da pulsão de vida. Quando isso não acontece, o gozo espalha-se, frui por todo o corpo, devastando-o. Às vezes, a solução é investir numa reeconomia de gozo, ou seja, na redistribuição de gozo para salvar o sujeito da autodestruição.

A dor, como a esfinge, precisa ser decifrada para não devorar o doente no usufruto do gozo.

\section{Referências}

Chemama, R. (1995). Dicionário de psicanálise. Porto Alegre: Artes Médicas.

Costa, R. S. C. (2009). As dores corporais na fibromialgia: reflexões psicanalíticas. Dissertação de Mestrado. Programa de Pós-Graduação em Psicologia Clínica da Universidade Católica de Pernambuco.

Creder, M. (2002). A dor como metáfora da unidade. Dissertação de Mestrado. Programa de Pós-Graduação em Psicologia Clínica. Universidade Católica de Pernambuco.

Engel, G. L. (1975). Dor. In MacBryde. Sinais e sintomas (5 ${ }^{\text {a }}$ ed.). Rio de Janeiro: Guanabara Koogan.

Fontes, I. (2002). Memória corporal e transferência: fundamento para uma psicanálise do sensível. São Paulo: Via Lettera.

Forbes, J. et al. (Orgs.) (2005). A invenção do futuro. Um debate sobre a pósmodernidade e a hipermodernidade. Barueri, SP: Manole.

${ }^{1}$ Realço o termo purificação relacionando-o ao sentido de sublimação: um processo químico que Freud tomou emprestado para indicar um movimento de ascensão ou de elevação da pulsão para alvos sublimes.

Rev. Latinoam. Psicopat. Fund., São Paulo, v. 15, n. 4, p. 851-867, dezembro 2012 
Freud, S. (1977). Projeto para uma psicologia científica. Luto e Melancolia. In Edição Standard Brasileira das Obras Psicológicas Completas de Sigmund Freud (v. 1). Rio de Janeiro: Imago. (Trabalho original publicado em 1950-[1895])

Freud, S. (1977). Repressão. In In Edição Standard Brasileira das Obras Psicológicas Completas de Sigmund Freud (v. 14). Rio de Janeiro: Imago. (Trabalho original publicado em 1915)

Freud, S. (1977). Rascunho G. Melancolia. In Edição Standard Brasileira das Obras Psicológicas Completas de Sigmund Freud (v. 1). Rio de Janeiro: Imago. (Trabalho original publicado em 1950-[1892-1899])

Freud, S. (1977). Luto e melancolia. In Edição Standard Brasileira das Obras Psicológicas Completas de Sigmund Freud (v. 14). Rio de Janeiro: Imago. (Trabalho original publicado em 1917[1915])

Freud, S. (1977). O problema econômico do masoquismo. In Edição Standard Brasileira das Obras Psicológicas Completas de Sigmund Freud (v. 19). Rio de Janeiro: Imago. (Trabalho original publicado em 1924)

Freud, S. (1977). Inibição, sintoma e ansiedade. In Edição Standard Brasileira das Obras Psicológicas Completas de Sigmund Freud (v. 20). Rio de Janeiro: Imago. (Trabalho original publicado em 1926-[1925])

International Association for the Study of Pain. Recuperado em 25 outubro 2009, do www.iasp-pain.org.br.

Lacan, J. (1979). O seminário. Livro 1. Os escritos técnicos de Freud. Rio de Janeiro: Jorge Zahar. (Trabalho original publicado em 1953-1954)

Lacan, J. (1985). O seminário. Livro 2. O eu na teoria freudiana e na técnica da psicanálise. Rio de Janeiro: Jorge Zahar. (Trabalho original publicado em 1954-1955)

Lacan, J. (2001). O seminário. Livro 14. A lógica da fantasia. Rio de Janeiro: Jorge Zahar. (Trabalho original publicado em 1966-1967)

Lacan, J. (1982). O seminário. Livro 20. Mais... Ainda. Rio de Janeiro: Jorge Zahar. (Trabalho original publicado em 1972-1973)

Lacan, J. (2007). O seminário. Livro 23. O Sinthoma. Rio de Janeiro: Jorge Zahar. (Trabalho original publicado em 1975-1976)

Lacan, J. (1991). Intervenciones y textos ( $2^{\mathrm{a}}$ ed.). Buenos Aires: Manantial.

Lipovetsky, G. (2004). Les temps hypermodernes. Paris: Grasset.

Miller, J-A. (2000). Os seis paradigmas do gozo. Revista Orientação Lacaniana, Rio de Janeiro, 27, 87-105.

Miller, J-A. (2008). La experiência de lo real en la cura psicoanalítica (cap. 21, pp. 371-386). Buenos Aires: Paidós.

Nasio, J-D. (2007). Mon corps et ses images. Paris: Payot.

Pereira, F. M. G. (2006). Tatuagens, piercings e outras intervenções corporais. Aproximações interetnográficas entre Recife e Madri. Tese de Doutorado em Antropologia. Universidade Federal de Pernambuco.

Pommier, G. (2005). Qué es lo “real”. Ensayo psicoanalítico (cap. 14, pp. 159-173). Buenos Aires: Nueva Visión. 
Queiroz, E. F. (2007). Trama do olhar. São Paulo: Casa do Psicólogo.

Rocha, Z. J. B. (2011). A dor física e psíquica na metapsicologia freudiana. Revista Mal-estar e Subjetividade, Fortaleza, 11(2), 591-621, jun.

Roudinesco, E. \& Plon, M. (1998). Dicionário de psicanálise. Rio de Janeiro: Jorge Zahar.

Serviços de tratamento da dor. Recuperado em 4 julho 2008 do www.portal.saude.gov.br.

Siqueira, E. R. A. (2009). O estatuto contemporâneo das identificações em sujeitos com marcas e alterações corporais. Dissertação de Mestrado. Programa de Pós-Graduação em Psicologia Clínica da Universidade Católica de Pernambuco.

Sociedade Brasileira para o Estudo da Dor. Recuperado em 4 julho 2008 do http:// www.dor.org.br.

\section{Resumos}

(Pain and jouissance: from Freud to Lacan)

The phenomenon of chronic pain has led researchers to broaden their understanding of pain beyond the sensory sphere and recognize its sociocultural and psychological dimensions. For psychoanalysts, pain is evidence of a drive in the body. The problem of pain and its relation to jouissance are discussed from the point of view of Freudian and Lacanian metapsychology. From the Freudian perspective, pain is governed by the principle of pleasure-displeasure, whereas from Lacan's point of view, jouissance refers to what lies beyond this principle. In other words, it is related to the death drive.

Key words: Physical pain, drive, representation, enjoyment

(La douleur et la jouissance: de Freud à Lacan)

Le phénomène de la douleur chronique a forcé les chercheurs à élargir leur compréhension de la douleur au-delà des phénomènes sensoriels et de reconnaître la douleur socio-culturelle et psychologique. Pour les psychanalystes, la douleur est un témoignage de la présence de la pulsion dans le corps. Nous discutons le problème de la douleur et son rapprochement à la jouissance du point de vue de la métapsychologie freudienne et lacanienne. Chez Freud, la douleur est régie par le principe de plaisirdéplaisir, tandis que chez Lacan, la jouissance se réfère à ce qui se trouve au-delà de ce principe, c'est à dire, à ce qui se lie à la pulsion de mort.

Mot clés: Douleur corporelle, représentation, circuit pulsionnel et jouissance

(El dolor y el gozo: de Freud a Lacan)

El fenómeno del dolor crónico obligó a los investigadores a ampliar su comprensión del dolor más allá de los fenómenos sensoriales y reconocer la dimensión 
socio-cultural y psicológica del dolor. Para los psicoanalistas el dolor es un testimonio de la presencia de la pulsión en el cuerpo. Se discute el problema del dolor y su enfoque para el gozo desde la perspectiva de la metapsicología freudiana y lacaniana. En la perspectiva freudiana, el dolor se rige por el principio del placer-displacer, mientras que en la lacaniana, el gozo se refiere a lo que está más allá de este principio, es decir, se relaciona con la pulsión de muerte.

Palabras claves: Dolor corporal, representación, circuite pulsional, gozo

(Schmerz und Lust: von Freud bis Lacan)

Das Phänomen des chronischen Schmerzens hat die Forscher gezwungen, ihre Auffassung von Schmerz über die sensorischen Äußerung hinaus zu erweitern und die sozio-kulturelle so wie die psychische Dimension des Schmerzens mit einzubeziehen. Für die Psychoanalytiker zeugt der Schmerz von einem körperlichen Trieb. Hier werden die Problematik des Schmerzens und ihre Nähe zur Lust aus der metapsychologischen Sicht von Freud und Lacan besprochen. Aus freudscher Perspektive wird der Schmerz vom Prinzip der Lust und Unlust bestimmt; aus lacanscher Sicht steht Lust eher in Zusammenhang mit dem, was über dieses Prinzip hinaus geht, d. h. es steht in Verbindung mit dem Todestrieb.

Schlïsselwörter: körperlicher Schmerz, Trieb, Darstellung, Lust

Citação/Citation: Queiroz, E. F. de (2012, dezembro). Dor e gozo: de Freud a Lacan. Revista Latinoamericana de Psicopatologia Fundamental, 15(4), 851-867.

Editor do artigo/Editor: Prof. Dr. Manoel Tosta Berlinck

Recebido/Received: 4.10.2011 / 10.4.2011 Aceito/Accepted: 15.8.2012 / 8.15.2012

Copyright: () 2009 Associação Universitária de Pesquisa em Psicopatologia Fundamental/ University Association for Research in Fundamental Psychopathology. Este é um artigo de livre acesso, que permite uso irrestrito, distribuição e reprodução em qualquer meio, desde que o autor e a fonte sejam citados / This is an open-access article, which permits unrestricted use, distribution, and reproduction in any medium, provided the original author and source are credited.

Rev. Latinoam. Psicopat. Fund., São Paulo, v. 15, n. 4, p. 851-867, dezembro 2012 


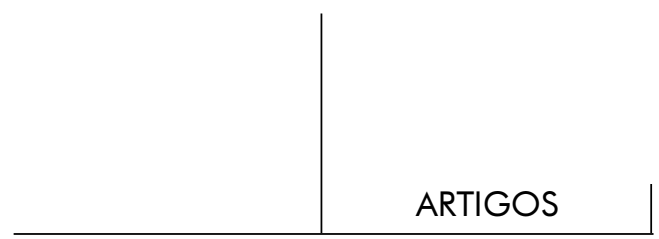

Financiamento/Funding: Esta pesquisa é financiada pelo Conselho Nacional de Desenvolvimento Científico e Tecnológico - CNPq / This research is funded by the Conselho Nacional de Desenvolvimento Científico e Tecnológico - CNPq

Conflito de interesses/Conflict of interest: A autora declara que não há conflito de interesses / The author declares that has no conflict of interest.

\section{Edilene Freire de QueIroz}

Psicanalista; Doutora em Psicologia Clínica pela Pontifícia Universidade Católica de São Paulo - PUC-SP (São Paulo, SP, Br); Pós-doutora pelo Laboratoire de Psychopathologie Clinique, Université de Aux-Marseille I (Aux-Marseille, Fr); Professora Titular e membro do Programa de Pós-graduação em Psicologia Clínica da Universidade Católica de Pernambuco - UNICAP (Recife, PE, Br); Coordenadora do Laboratório de Psicopathologia Fundamental e Psicanálise e Coordenadora Geral de Pesquisa da UNICAP; Membro da Associação Universitária de Pesquisa em Psicopatologia Fundamental (São Paulo, SP, Br); Membro do Grupo de Pesquisa do Conselho Nacional de Desenvolvimento Científico e Tecnológico - CNPq: Psicologia Clínica/UNICAP; Pesquisadora P-2 do CNPq.

Praça de Casa Forte, 354/1402 - Casa Forte

52061-420 Recife, PE, Br

Fone: (81) 3268-5482

e.mails: equeiroz@unicap.br e edilenefreiredequeiroz@gmail.com 